\title{
Response to Pazderka and Schroeder
}

\section{Réponse à Pazderka et Schroeder}

\author{
by PAUL GROOTENDORST \\ Faculty of Pharmacy, University of Toronto \\ Toronto, ON \\ LIVIO DI MATTEO \\ Department of Economics, Lakehead University \\ Thunder Bay, ON
} government lengthened the period of market exclusivity afforded to patented drugs. They suggest that this increase has to be explained by factors other than the policy change. We disagree - we are not aware of any other factors that could explain as effectively the dramatic increase in $\mathrm{R} \& \mathrm{D}$. That is why we believe that, had the Patent Act revisions not been made, domestic pharma $R \& D$ would have been much lower. We recognize that some of the additional domestic pharma $R \& D$ spending might have been shifted from other jurisdictions (so that global R\&D increased by less than domestic R\&D). OECD data, however, suggest that international pharma $R \& D$ increased markedly after 1987, and the Patent Act changes may have played a role. 
Schroeder expresses concerns about our "simplistic" assumptions, "questionable" calculation of expenditures and "inconsistencies" in our definition of R\&D expenditures, but does not identify specific issues. It is therefore difficult to respond to his concerns. For instance, we assessed the effect of the Patent Act changes on two different measures of pharma $R \& D$ to ensure that our results were reasonably robust. (They were.) His criticism of our use of the motor vehicle industry R\&D as a comparator to pharma $R \& D$ is clearer. He argues that the "motor vehicle industry is much less dependent on patent protection than the pharmaceutical industry, and investment in $R \& D$ in the Canadian motor vehicle industry has been artificially inflated by the Auto Pact agreement with the United States." These statements may be true, but it does not follow that the change in motor vehicle sector $R \& D$ cannot reflect the effects of factors like changes in federal and provincial $R \& D$ tax credits on pharma $R \& D$. Both are capital intensive industries composed of large multinational corporations who exercise discretion over the location of their $\mathrm{R} \& \mathrm{D}$ - it is unclear why inter-industry differences in the degree of reliance on intellectual property protection would matter.

Schroeder further characterizes our comparison of drug cost growth in Canada to that in the US as "misguided." We agree that patent approval times are shorter in the US, but while differences like these might affect the level of drug costs in the two countries, they do not invalidate a comparison of pre-post 1987 changes in drug costs in the two countries. We agree with Schroeder that the Patent Act changes likely have delayed generic competition until after sales of the brand drug have peaked - this is undoubtedly one of the sources of the increase in drug costs we observed after 1996.

Schroeder points to several difficulties in valuing the health gains from the increase in pharma $\mathrm{R} \& \mathrm{D}$. Our calculations are based on averages reported in the literature - the mean cost of developing NMEs, the mean health gain from NMEs and mean willingness to pay for health gains. We certainly agree that the value of the drugs actually developed on account of the Patent Act changes could be higher or lower - our intent was to determine the order of magnitude of the estimated value of the policy. That being said, we disagree with the criticism that "... it is extremely unlikely that the domestic R\&D environment would be capable of producing four to six NMEs independently, that an additional \$4-6 billion invested in R\&D would result in drugs launched solely out of Canada, or that they would be developed exclusively for the small Canadian market." We did not state that the additional NMEs that could be supported with the additional outlays on pharma R\&D would necessarily be developed entirely in Canada; indeed, we stated that most domestic R\&D involves safety and efficacy testing of drugs developed elsewhere. Nevertheless, such testing is a necessary part of the R\&D that might not have occurred without the policy change, and the drugs that were developed on account of this $R \& D$ were likely of value to Canadians (and others as well). 